\title{
As cores fisiológicas na ciência de Goethe: educação e fenomenologia
}

\author{
Physiological colors in the science of Goethe: \\ education and phenomenology
}

Jonas Bach Junior ${ }^{1}$

\begin{abstract}
Resumo: Este artigo apresenta o ponto de partida de Goethe para a formulação de sua Teoria das Cores. A observação fenomenológica das cores fisiológicas é base fundamental para uma concepção hologramática do fenômeno cromático. Com seu método de pesquisa, Goethe não reduziu o fenômeno a representações mecânicas ou geométricas, mas focou sua dimensão qualitativa. A complementariedade das cores fisiológicas é um princípio inerente tanto ao todo, quanto às partes da Teoria das Cores. A fenomenologia da natureza de Goethe é uma unidade dinâmica entre subjetividade e objetividade. Sua compreensão exige a execução de um processo de educação dos sentidos e de educação para uma cognição qualitativa.

Palavras-chave: Teoria das cores. Goethe. Fenomenologia da natureza. Educação.
\end{abstract}

\begin{abstract}
This paper presents the starting point of Goethe to formulate his Theory of Colors. The phenomenological observation of physiological colors is the fundamental basis for the hologrammatic conception of the chromatic phenomenon. With his research method, Goethe did not reduce the phenomenon in mechanical or geometric representations, but focused on its qualitative dimension. The complementarity of physiological color is inherent to both the whole and the parts of the Theory of Colours. The phenomenology of nature for Goethe is a dynamic unity between subjectivity and objectivity. To be understood, it requires the execution of an educational process using the senses and qualitative cognition.
\end{abstract}

Keywords: Theory of colors. Goethe. Phenomenology of nature. Education.

\footnotetext{
${ }^{1}$ Universidade Estadual de Campinas (UNICAMP), Departamento de Filosofia da Educação, Campinas, SP, Brasil. E-mail: <jonasbachjr@yahoo.com.br>
} 


\section{Introdução}

Johann Wolfgang von Goethe (1749-1832) acumulou, pelo menos, duas décadas de observações meticulosas no campo do fenômeno das cores, para, mais tarde, publicá-las como sua Teoria das Cores, em 1810. Nesta obra, além de uma detalhada descrição dos resultados obtidos por meio de sua pesquisa, Goethe expõe indiretamente seu método científico, reconhecido, atualmente, como fenomenológico ${ }^{2}$.

Este estudo propõe apresentar a fenomenologia da natureza de Goethe conjuntamente ao ponto de partida de sua teoria das cores, procurando trazer à compreensão ambos, tanto seu processo de pesquisa quanto os resultados obtidos. Por ter se contraposto a Newton em sua teoria das cores, tanto a metodologia de Goethe quanto as suas obras científicas - sobretudo, na botânica ( $A$ metamorfose das plantas) e na ótica (Teoria das cores) - tiveram lenta aceitação ao longo da história da ciência, uma vez que não coadunavam com o paradigma da sua época (entre os séculos XVIII e XIX). Somente no século XX, quando a epistemologia e a filosofia contemporâneas imbuíram-se de uma nova linguagem, a metodologia goetheana passou a ser reconhecida. Foi justamente a fenomenologia que tornou possível a construção de um paradigma que permitiu a aceitação e compreensão da visão científica de Goethe.

Como fenomenologia da natureza, o método de pesquisa de Goethe tem implicação no campo da educação, ao fundar um processo de aquisição do conhecimento que não busca a dicotomização entre sujeito e objeto. Ao enfatizar a formação do sujeito em seu aperfeiçoamento em relação às impressões sensoriais, a fenomenologia da natureza possui desdobramentos para a prática educativa ao percorrer processos paradigmáticos diferenciados em comparação ao reducionismo dos modelos matemáticos, herdados do passado como referências referendadas e estabelecidas. Nestes termos, a fenomenologia da natureza se apresenta como processo complementar aos métodos científicos vigentes, evitando, assim, absolutizações e unilateralidades presentes em qualquer formação reducionista. Deste modo, este estudo vem colaborar na proposição de um processo educativo dialógico, tendo a natureza como parceira ativa e o método de pesquisa de Goethe como suporte dialógico e intermediador.

\section{Ótica fenomenológica}

A Teoria das Cores tem uma estrutura fundamentalmente interdisciplinar, é somente como um todo que pode ser realmente compreendida sem, no entanto, menosprezar as partes que configuram esse todo. Assim, Goethe (1993) subdivide suas descrições das observações em três categorias: cores fisiológicas, físicas e químicas, indicando uma interdisciplinaridade entre

\footnotetext{
${ }^{2}$ Por abordar a essência do fenômeno, o método científico de Goethe foi reconhecido como fenomenológico somente no século XX. Seamon (2013) reúne uma abordagem geral sobre a fenomenologia de Goethe, dos seus fundamentos epistemológicos e filosóficos à prática da ciência. A leitura a respeito do tema em língua portuguesa é rara, por isso, a correlação entre Goethe e fenomenologia ainda causa surpresas. Os estudos comparativos com a fenomenologia de Husserl são incipientes. O campo comum entre ambas as fenomenologias é a compreensão da essência, a diferença fundamental está na assunção do estudo dos sentidos humanos por parte de Goethe, enquanto Husserl focou no ego transcendental.
} 
a fisiologia, a física e a química, para culminar na significância das cores em termos estéticos e morais, como fenômeno incluso dentro do psicológico e filosófico. "É difícil dizer se a Teoria das Cores pertence ao reino da física, fisiologia ou psicologia. Ela não pertence a nenhuma delas e, ao mesmo tempo, a todas" (BORTOFT, 2013, p. 60, tradução nossa).

A preocupação principal de Goethe era pesquisar o universo das cores como fenomenólogo. Como princípio metodológico, suas observações foram realizadas empiricamente, por meio de repetidos experimentos que realizou para descobrir, dentre as diferentes condições ambientais, o que ele chamava de fenômeno primordial (Urphähomen).

Em relação às cores como manifestações fenomênicas, elas foram categorizadas de acordo com o padrão de transitoriedade e durabilidade da manifestação. Cores fisiológicas, físicas e químicas diferenciam-se segundo uma questão de temporalidade da manifestação. As cores fugidias, rápidas e efemeramente transitórias são um fenômeno produzido pelo olho humano, e foram denominadas por Goethe de cores fisiológicas. As cores temporárias, com certa duração dependendo das condições externas, foram classificadas como fenômenos das cores físicas. Por último, a cores permanentes, fixas e ligadas aos objetos, são as cores químicas.

O modo de classificar a manifestação das cores é, em si, parte integrante do método fenomenológico. O critério classificador não é arbitrário, é oriundo da postura dialógica de Goethe como pesquisador, que estabelecia uma relação com a natureza e na natureza. Neste ponto, se apresenta a postura metodológica oposta à de Newton, que procurava uma pesquisa sobre a natureza. Ambos chegaram a resultados diametralmente opostos, que podem ser expressos como entre um pensamento sobre as coisas [aboutness-thinking] e um pensamento com as coisas [withness-thinking] (SHOTTER, 2005, p. 141).

A classificação, não sendo arbitrária, é participativa, ou seja, o fenômeno, a natureza, "indica", por meio dos seus modos de manifestação, como o fenômeno precisa ser compreendido. O papel do pesquisador, nesta postura participativa e dialógica com e na natureza, é de auscultar esta linguagem da natureza para que a pesquisa esteja em sintonia com o próprio objeto.

A relação entre a durabilidade e a efemeridade da manifestação do fenômeno das cores revela qualidades fenomênicas diferenciadas. A diferença entre estas qualidades não foi contemplada pela teoria de Newton, que, devido ao seu método, orienta a pesquisa numa direção oposta.

Goethe experimentou desenvolver uma física da cor que era baseada na experiência cotidiana. Ele se esforçou em alcançar um todo autêntico permanecendo no fenômeno, em vem de substituí-lo com uma representação matemática. (BORTOFT, 2013, p. 289, tradução nossa)

A constatação das diferenças qualitativas das manifestações das cores requer a ativa participação do pesquisador, pois, como método fenomenológico, a Teoria das Cores perde sua funcionalidade se limitada a mera transmissora de informação.

Experimentos devem se tornar concentrados, contínuas experiências através das quais se pode aprender novos modos de ver. Dado este deslocamento do produto pelo processo, pode-se entender a repetida insistência de Goethe que seu trabalho científico precisava ser feito para ser compreendido. (AMRINE, 2013, p. 42, tradução nossa) 
Por outro lado, se compreendida como ensejo para que outros pesquisadores ativem em si mesmos a processualidade fenomenológica do seu método, a Teoria das Cores passa a ser incentivo para uma nova formação do pesquisador que não repete os reducionismos do passado.

A fenomenologia das cores não reproduz a unilateralidade da objetividade exclusiva, pois sem o olho, sem o ato perceptivo do olhar, não há cores. O experimento é a atitude pesquisante que cria a experiência do sujeito, para servir como intermediário ao objeto. A fenomenologia de Goethe não afirma a preponderância da exclusividade, ou subjetividade, ou objetividade, mas afirma ambas numa dinâmica viva inter-relacionante.

A coerência da classificação não é constatada pelo escrutínio de uma racionalidade limitadora do espectro fenomenológico. A experiência da evidência dessa coerência requer o desenvolvimento do pesquisador em sua capacidade de julgamentos intuitivos [anschauende Urteilskraft]. De uma certa maneira, o pré-requisito para engendrar a fenomenologia da natureza é, a um só tempo, a criação das condições necessárias nas capacidades cognitivas do sujeito pesquisante. A própria biografia de Goethe é uma demonstração de que esta faculdade cognitiva não é herdada, mas adquirida por meio de um processo de vida que engloba um exercício dialogante com os fenômenos da natureza, onde o pesquisador aciona, em si mesmo, um processo de autoaperfeiçoamento tanto em relação aos seus sentidos, às suas percepções sensoriais, quanto ao seu processo reflexivo, que, no caso de Goethe, era dinâmico entre atividades analógicas e sintetizantes. Como ele mesmo expressou, sua busca era ativar em si a eterna dinâmica entre sístole e diástole.

Não é suficiente aplicarmos na observação da natureza o processo analítico, ou seja, que a partir de um objeto qualquer dado, passemos a desenvolver tantas particularidades quanto possível e a conhecê-las desta maneira, mas temos também que aplicar a mesma esta mesma análise à síntese existente, para pesquisar se procedemos, então também, corretamente de acordo com o verdadeiro método. (GOETHE, 2000c, p. 50, tradução nossa)

Em outras palavras, o modo de expressão da natureza foi o exemplo educativo e formativo da pesquisa de Goethe, que procurou incorporar a mesma capacidade dinâmica no seu modo de fazer pesquisa.

\section{Cores fisiológicas: sem o olho não existe a cor}

As cores fisiológicas são o ponto de partida da Teoria das Cores, "pois pertencem, no todo ou em grande parte, ao sujeito, ao olho. São o fundamento de toda a Teoria e nos revelam a harmonia cromática, que deu origem a tantos conflitos" (GOETHE, 1993, p. 53). Por serem fugidias e produzidas pelo olho, já foram consideradas espectros, ilusões de ótica. Como fenômenos isolados e a partir de uma perspectiva científica excludente e reducionista, foram relegadas e banidas de estudos mais aprofundados. Embora excluídas das considerações de outros pesquisadores, Goethe inclui as cores fisiológicas como parte inerente e integrante ao fenômeno da visão, "pois pertencem ao olho saudável e são consideradas condições necessárias à visão; indicam uma viva alternância interna e externa no olho" (GOETHE, 1993, p. 53).

Goethe elabora uma fenomenologia da percepção visual, iniciando com o efeito que a luz e a escuridão exercem sobre o olho. A condição sine qua non para a manifestação das cores 
expressa o fundamento do que Goethe chamava de fenômeno primordial, a polaridade da luz e da escuridão atendem a essa condicionalidade. O conceito de complementaridade está conectado ao conceito de polaridade. Como evidência da realidade fenomênica na percepção ocular, o olho cria uma polaridade por intermédio da ação da retina que, "segundo o efeito sobre ela exercido pela luz ou escuridão, se encontra em dois estados inteiramente opostos" (GOETHE, 1993, p. 54). A polaridade externa ao sujeito (ambiente) está relacionada à polaridade interna (olho), que varia entre a "máxima distensão e sensibilidade" e a "extrema tensão e insensibilidade".

Luz e escuridão externas se relacionam com a dinâmica da sensibilidade ocular, através da retina, para determinar a qualidade da percepção. Esta é a base para a compreensão da percepção de imagens pretas e brancas que, "incidindo ao mesmo tempo no olho, produzem, juntas, os mesmos estados que luz e escuridão sucessivamente" (GOETHE, 1993, p. 55-56).

Goethe trabalha aqui com cores que percebemos, porém, que não estão nos objetos, fora do corpo, mas que são cores que percebemos porque o olho as produz. Esta produção de cor pelo olho é um fenômeno inerente ao sentido da visão. Sua fenomenologia da percepção visual aborda uma manifestação que ocorre abaixo do nível de captação da consciência imersa no cotidiano da vida. Para a constatação desse fenômeno, Goethe realizava experimentos com forte contraste entre preto e branco, escuridão e luz. Para uma forte imagem clara, o olho cria a correspondente imagem complementar escura, e vice-versa. $\mathrm{O}$ fenômeno da visão está intrinsecamente relacionado ao fenômeno fisiológico ocular. O olho é um ser criador de complementaridade em relação ao que ele capta em seu ambiente.

Quase não notamos isso na vida cotidiana, pois raramente ocorrem imagens em forte contraste. Evitamos olhar para aquelas que ofuscam. A sucessão de imagens nos parece pura: ao olharmos de um objeto a outro, não percebemos que algo da imagem anterior furtivamente se insinua na seguinte. (GOETHE, 1993, p. 57)

As cores fisiológicas são percebidas quando as condições nas quais o sujeito perceptor se encontra lhe permitem perceber essa "inércia" do olho que, ao criar a imagem complementar diante de um objeto, a mantém por um certo tempo - daí a sua transitoriedade - mesmo quando o olho já está diante de outro objeto.

No capítulo inicial da Teoria das Cores, Goethe incluiu, também, a problematização das patologias oculares, que podem distorcer a qualidade das percepções. As imagens remanescentes, os espectros, a conscientização da manifestação das cores fisiológicas se tornam, assim, critérios de maior fidelidade nos experimentos óticos, quando Goethe adverte para "tomar cuidado para não misturar o espectro remanescente de uma observação anterior com a seguinte, tornando-a confusa e impura" (GOETHE, 1993, p. 59).

O fenômeno em si de percepção das cores exige a concomitância dos pares opostos e complementares de luz e escuridão. "Escuridão não é uma total ausência passiva de luz como Newton tinha sugerido, mas, na verdade, uma presença ativa opondo-se à luz e interagindo com ela" (SEAMON, 2013, p. 6, tradução nossa). Se a escuridão plena é a negação da percepção ocular, a iluminação plena ofusca, e, na sua atuação oposta, produz o mesmo efeito, ou seja, a anulação da percepção. Como condição, então, à percepção, ambos devem estar presentes no ambiente. Percepção de cores exige, como condição, a simultaneidade de luz e escuridão. 
Nesta relação, o olho é um contínuo criador de complementaridade para, na sua interação com o ambiente, formar uma totalidade.

Ele [olho] não pode e nem quer em momento algum permanecer idêntico num estado específico determinado pelo objeto. Ao contrário, é forçado a uma oposição, na medida em que contrapõe um extremo ao outro, o intermediário ao intermediário, unindo ao mesmo tempo os opostos e almejando, sucessivamente ou no mesmo espaço e tempo, à totalidade. (GOETHE, 1993, p. 60, grifo nosso)

Polaridade, complementaridade, e totalidade são conceitos que a fenomenologia de Goethe evidencia como termos próprios à linguagem da natureza. A linguagem fenomenológica, então, é mimética, porque a relação dialógica com a natureza imbui o sujeito de uma capacidade mimética em relação ao fenômeno (LINDHOLM, 2008, p. 58). O pesquisador fica incumbido, como fenomenólogo, de adquirir a capacidade de perceber esta linguagem e expressá-la. Sua interpretação não é um jogo arbitrário, mas uma atividade coparticipativa com o fenômeno, na natureza, para expressar, num modo linguístico, o que ela mesma tem para se revelar.

A multiplicidade de experimentos óticos é outro fator que demonstra o método fenomenológico goetheano. $\mathrm{O}$ foco está no estudo das diversas condições para surgimento do fenômeno. A variação de experimentos aborda imagens cinzas, incolores, coloridas e sombras coloridas, para abordar o comportamento fisiológico do olho, determinante da nossa qualidade perceptiva. Goethe expressou sua crítica aos sentidos, contrapondo-se à trilogia kantiana que abordou a razão e os julgamentos humanos.

Kant nos chamou a atenção para o fato de haver uma crítica da razão e de esta faculdade, que é a mais elevada que o homem possui, ter bons motivos para ficar atenta a si mesma. Que grande vantagem esta voz nos trouxe, isto é algo que cada um pode colocar em si mesmo à prova. Eu, contudo, no mesmo sentido, gostaria de colocar a seguinte tarefa: é necessária agora uma crítica dos sentidos... (GOETHE, 2003, p. 113)

Luz e escuridão, cada uma em si mesma, são situações extremas. O cinza é a moderação entre o claro e o escuro. A percepção do cinza, ou melhor, do grau de escuridão ou claridade do cinza, pode variar de acordo com o fundo onde a imagem se encontra. "A mesma imagem cinza sobre um fundo preto parece muito mais clara do que a mesma imagem sobre um fundo branco" (GOETHE, 1993, p. 61). O experimento proporciona a constatação dessa experiência com uma mesma imagem cinza, pois, na relação com o fundo preto, o olho cria a complementaridade da claridade, que influi na percepção da qualidade do cinza, que parece mais claro (Figura 1). Com o fundo branco, o olho torna-se complementarmente escuro, mudando a qualidade de percepção do cinza, que parece mais escuro. Guimarães (2004, p. 58) denomina este fenômeno de padrão visual composto, onde "classificar as informações cromáticas em claras e escuras implica a utilização de uma estrutura comparativa". 
Figura 1. Contraste entre o cinza e o fundo preto e branco ${ }^{3}$
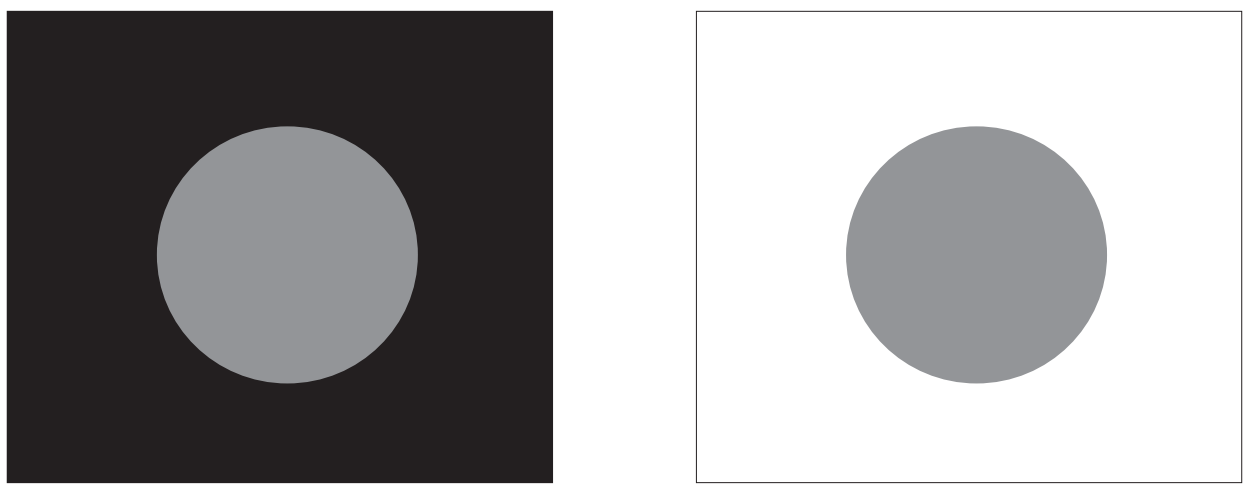

Fonte: elaborado pelo autor.

A qualidade da percepção não está somente no objeto, a dinâmica fisiológica do olho é codeterminante da percepção. Uma fenomenologia do ato de ver engloba o papel complementar que realiza a correspondência entre o interno e o externo, entre o sujeito e o objeto, entre o perceptor e o percebido. A correspondência é o aspecto interativo do olho com o seu ambiente.

Podemos notar novamente nesse caso a grande sensibilidade da retina e o protesto tácito que cada ser vivo é levado a fazer quando qualquer estado específico lhe é apresentado. É assim que a inspiração pressupõe a expiração e vice-versa, como cada sístole sua diástole. A fórmula eterna da vida também aqui se manifesta. Se oferecemos o escuro ao olho, ele requer o claro e, quando se lhe contrapõe o claro, ele evoca o escuro, mostrando assim sua vitalidade, seu direito de apreender o objeto, produzindo, por si mesmo, algo que é contraposto ao objeto. (GOETHE, 1993, p. 61)

A diversificação e repetição de experimentos abrange a multiplicidade dos fenômenos cromáticos. Este é um lado da abordagem fenomenológica goetheana. A busca da compreensão da natureza como unidade dinâmica e viva geradora da multiplicidade é o outro lado da abordagem epistemológica. Unidade e multiplicidade compõem a sístole e a diástole do processo dinâmico de construção do conhecimento na fenomenologia goetheana. Somente unidade ou somente multiplicidade não revelam a realidade da natureza. A fenomenologia da natureza é um processo cognitivo que incorpora a unidade e a multiplicidade nos seus pressupostos. Ao realizar o experimento com a imagem cinza (uma multiplicidade do fenômeno cromático),

\footnotetext{
${ }^{3} \mathrm{O}$ círculo cinza inserido no fundo preto possui a mesma tonalidade do cinza inserido no fundo branco. A sensação de maior escuridão ou claridade nos "dois cinzas" deve-se ao fenômeno de contra-atuação ocular.
} 
Goethe (1993) busca relacioná-lo com a unidade, o fenômeno primordial, a lei subjacente à manifestação fenomênica que se expressa na complementaridade dos opostos, na qual o olho é participativo. A essência do olho é a sua intencionalidade; seu modo de ser se expressa como criação de complementaridade ou como formador de totalidade.

A complementaridade é a "fórmula eterna da vida", assim, o processo de pesquisa deve perpassar a multiplicidade e voltar à unidade e da unidade à multiplicidade. Esta dinâmica epistemológica é inerente à processualidade da fenomenologia de Goethe. Cada experimento ótico é ensejo de, na experiência com a multiplicidade, religá-la ao fundamento do mundo. Como formação da subjetividade, esta fenomenologia conecta o sujeito ao objeto para que ele possa realizar percepções que se elevem do nível trivial e que o elevem de uma relação comum com o mundo. A postura metodológica de Goethe se revela fenomenológica ao desenvolver, no sujeito, sua atenção para a própria dinâmica de sua consciência, pois o que os sentidos transmitem é insuficiente, porém não supérfluo, descartável ou excluível. A insuficiência dos sentidos requer a complementação de um trabalho superior na dinâmica racional do sujeito cognoscente, ao buscar desenvolver, em si, capacidades cognitivas que não são espontâneas, mas adquiridas por meio de um treinamento reflexivo que incorpora uma dinâmica dialógica com o fenômeno.

Nos experimentos com imagens ofuscantes, que emitem luz, o estudo foi dirigido para o que é percebido quando o olho se volta a diversas superfícies, claras, escuras, cinzas, onde foi possível constatar que o olho produz cor. "Quando se vê uma imagem ofuscante completamente incolor tem-se uma impressão profunda e duradoura, cuja extinção é acompanhada por um fenômeno cromático" (GOETHE, 1993, p. 61). A variação das condições é um requisito para explorar o múltiplo, o maior número possível de possibilidades. O fenômeno cromático que se manifesta neste caso é relativo, pois depende da interação do olho com a cor da superfície que ele aborda. A luz ofuscante incolor determina o estímulo que o órgão recebe, que permanece com atividade ocular temporária mesmo sem presença do objeto emissor do estímulo. A percepção da cor fisiológica é uma manifestação do estímulo inicial com a atividade complementar ocular que deixa uma "impressão duradoura"; esta interage com a cor da superfície produzindo a percepção de outra cor. O estímulo é incolor, a "impressão duradoura" é uma atividade determinante da percepção da cor da superfície.

A cor fisiológica não possui onda, não pode ser mensurada no sentido da física clássica newtoniana. Ela não pode ser localizada no objeto externo, é fenômeno no sujeito, do sujeito, porém, não é subjetiva no sentido de não pertencer à veracidade do fenômeno. Não é uma ilusão de ótica, a cor fisiológica é real, produção do órgão sensorial e percepção que este órgão mesmo realiza. A fenomenologia não parte da questão da objetividade do fenômeno, sua ênfase é o fenômeno sensorial em si. "Seria completamente injustificado denominá-los 'subjetivos' neste estágio da investigação porque, no nível dos fenômenos, não há nada a ser dito a este respeito" (HENSEL, 2013, p. 77-78, tradução nossa).

Compreender as cores na fenomenologia de Goethe pressupõe compreender o órgão sensorial. Importam, inicialmente, na abordagem fenomenológica, as condições para o surgimento do fenômeno. O fenômeno das cores surge porque possuímos olhos. O fenômeno olho surge porque existe luz. Este órgão sensorial se desenvolveu na luz, possui afinidade com a luminosidade. A função de correspondência do olho exerce uma continuidade entre o externo e o interno. "Assim o olho se forma na luz e para a luz, a fim de que a luz interna venha ao encontro da luz externa" (GOETHE, 1993, p.44). A subjetividade não tem papel passivo, de ser apenas "iluminada" pelos objetos externos, ela tem função ativa de iluminar. 
A estrutura de apresentação da Teoria das Cores é hologramática, respeitando a relação entre o todo e as partes, entre o universal e o particular, entre o fenômeno puro e os experimentos óticos. As cores fisiológicas, como primeira parte do todo da obra, já incluem a conexão com o fenômeno primordial (luz e escuridão) que permeia a obra como um todo. As outras partes, cores físicas e cores químicas, são relacionadas, igualmente, com o fenômeno primordial. Esta estruturação hologramática corresponde ao princípio de exposição da dinâmica do pensamento goetheano, que é justificada pelo autor em outros artigos científicos.

Tentei apresentar nas duas primeiras partes de minhas colaborações sobre as cores uma tal seqüência de experimentos que se aproximam e se tocam reciprocamente, que, quando se conhece todos e se consegue abrangê-los, apenas representam um único experimento, ou uma única experiência sob os mais variados aspectos. (GOETHE, 2000c, p. 18, tradução nossa)

Goethe não apresenta uma dinâmica reflexiva com um raciocínio causal e sequencial para que algum resultado seja apresentado no fim. A evidência, como fenômeno primordial, acompanha a obra em seu início, desenvolvimento e fim. Cada experiência não é tomada isoladamente para, então, se confirmar alguma hipótese, como Goethe (2000c) mesmo preconizou como base de seu método científico; mas, pelo contrário, a experiência é considerada em sua ligação com todos os outros fenômenos. Daí o caráter holístico da fenomenologia de Goethe. Sua intenção era uma pesquisa científica conectada com a vivacidade do fenômeno natural.

Na natureza viva nada acontece que não esteja em conexão com o todo, e quando as experiências se nos apresentam só isoladamente, e temos que considerar os experimentos fatos isolados, isso não quer dizer que elas sejam realmente isoladas. É somente a questão de como encontrar a conexão desses fenômenos, desses acontecimentos. (GOETHE, 2000c, p. 17 , tradução nossa)

A premissa "nada acontece sem estar em conexão com o todo" (GOETHE, 2000c, p. 17) considera toda experiência como isolada apenas em seu aspecto aparente. Como método de pesquisa, os procedimentos de Goethe visam o aspecto oculto do fenômeno que não se apresenta diretamente aos sentidos, porém, que tampouco pode ser preterido. Os experimentos óticos, então, possuem o papel de intermediários entre o sujeito e o objeto. Eles têm a função de desvendar a natureza essencial do objeto, ao mesmo tempo que são base de elaboração para o aprimoramento da subjetividade do próprio pesquisador, como o aguçamento dos sentidos e desenvolvimento das capacidades conceituais intuitivas. A Teoria das Cores não possui, então, um desenvolvimento reflexivo linear, mas hologramático. Assim como é necessário conhecer todos os experimentos (multiplicidade) e "abrangê-los" (unidade), a fenomenologia de Goethe exige que se tenha familiaridade com suas outras obras (multiplicidade) no campo científico e de seus princípios fundamentais (unidade).

O uso mediato dos experimentos contrapõe-se, como método, à busca de adequações de experimentos para que condigam com hipóteses pré-formuladas antes do encontro do pesquisador com o fenômeno. A estruturação ou ordenação da Teoria das Cores não foi formulada arbitrariamente, mas composta de acordo com a relação dialógica de Goethe com 
os experimentos, permitindo que a determinação da estruturação fosse orientada pelo próprio fenômeno, e não por representações construídas artificialmente. Como fenomenólogo em busca da essência das coisas mesmas, ou em busca do fenômeno primordial, cada experimento é testado segundo sua conexão com o todo.

Iniciando de um estudo mais simples, luz e escuridão, imagens brancas e pretas, cinzas, Goethe avançou para o estudo dos fenômenos coloridos, onde a manifestação fenomênica da complementaridade volta a se repetir e forma todo o fundamento de sua Teoria das Cores e de sua fenomenologia. Desse modo, ao incrementar uma variação na qualidade dos experimentos, cada um deles é verificado na sua conexão com o todo, com o fenômeno primordial apresentado desde o ponto de partida. O que se pode constatar, na sequência de relatos apresentados na Teoria das Cores, é a assunção das suas próprias diretrizes metodológicas, expressas no artigo Experiência e Ciência:

Quando experimentei a constância e seqüência dos fenômenos até certo grau, então estabeleço uma lei empírica e a prescrevo aos fenômenos futuros. Se lei e fenômenos condizem plenamente na seqüência, então eu ganhei, se eles não condizem completamente, reparo nas circunstâncias particulares e busco novas condições sob as quais posso expor mais puramente os experimentos em contradição. (GOETHE, 2000b, p. 24, tradução nossa)

As cores fisiológicas, para serem percebidas, necessitam, normalmente, da organização de um experimento à parte do fluxo da vida cotidiana, já que sua manifestação é fugidia e escapa à verificação num contexto cotidiano. Além disso, a situação de estar imerso num experimento coloca a atenção da consciência do pesquisador com um foco naquilo que pode se manifestar, enquanto, no cotidiano, a consciência pode estar ocupada com diversas outras questões e, assim, não permitir a verificação dessas manifestações. Isto não quer dizer que suas manifestações necessitem de condições complexas. É perfeitamente possível criá-las no ambiente escolar, por exemplo, sem que se necessite o emprego de uma grande estrutura. O que se ressalta aqui é que as condições para o surgimento das cores fisiológicas não estão sempre disponíveis no fluxo comum da vida. Como exemplo didático, a fenomenologia de Goethe pode ser aprendida e ensinada conjuntamente com os experimentos, assim, a unidade entre prática e teoria se faz dinâmica e presente no processo de aprendizado.

A fenomenologia de Goethe fundamentou uma ótica oposta aos princípios da física clássica de Newton ao basear-se num processo de elaboração e aprimoramento da relação do ser humano com o seu sentido visual. A base epistemológica cartesiana estrutura a principal obra de Newton (1996) sobre o tema. Em sua Óptica, Newton desenvolve os ideais da matematização da natureza, que foi o principal ponto de crítica por parte de Goethe. A questão fenomenológica não está no que os sentidos fornecem como dados de percepção, mas na atividade cognitiva do sujeito em julgar justamente estes dados. Desenvolver ciência, para Goethe, significa colocar o próprio ser humano numa dinâmica evolutiva de suas faculdades cognitivas e perceptivas. Sua ciência de base fenomenológica pressupõe, então, um processo de educação intrínseco, onde o cogito cartesiano é substituído por outra referência ontológica. $\mathrm{Na}$ fenomenologia da natureza, o eu penso o fenômeno não está separado do eu participo no fenômeno. O primeiro grau de participação no fenômeno acontece via percepção. A ciência fenomenológica exige a instrução dos sentidos para a experiência da evidência da essência. 
A metafísica da subjetividade instaurada na modernidade pela perspectiva cartesiana permitiu o controle sobre a natureza e seus desdobramentos no desenvolvimento tecnológico. Como resultado decorrente de um processo desenfreado de exploração dos recursos naturais e de expansão da presença da tecnologia na vida humana, temos o distanciamento em relação à natureza que, uma vez torturada, simplesmente se cala. O processo de educação por meio dos procedimentos fenomenológicos visa a postura dialógica do ser humano no seu encontro com a natureza. A transformação que o mundo precisa tem seu primeiro passo no sujeito que faz ciência.

\section{Considerações finais}

Por ser intrinsecamente interdisciplinar, a fenomenologia de Goethe envolve o fenômeno da ótica além dos auspícios da física, incluindo a compreensão da participação da fisiologia humana, sem a qual o fenômeno da percepção não se realiza. Aprender a conhecer está inter-relacionado a aprender a perceber. A fenomenologia da natureza é um processo de crítica dos sentidos humanos, concomitantemente ao processo de aperfeiçoamento da intuição conceitual diante do fenômeno. A educação crítica dos sentidos é uma relação dialógica com a natureza, evitando inferências que são uma tortura da natureza e deduções hipotéticas que são, antes, invenções que invadem a natureza com algo que não lhe diz respeito.

A educação crítica dos sentidos é o próprio processo de aprimoramento do pesquisador que não cai na unilateralidade da subjetividade ou da objetividade, mas que dinamiza ambas numa atividade inter-relacionadora entre o universal e o particular. Como metodologia de pesquisa, a fenomenologia de Goethe é, ao mesmo tempo, um processo educativo. A formação do sujeito pesquisante envolve um processo de observação minucioso e metódico, de ordenação do que foi observado a partir de uma congruência que reside no objeto, de dinamização e versatilidade das representações para compreensão ampla do fenômeno, e, por último, o desenvolvimento das capacidades cognitivas do sujeito. A abordagem desta metodologia é fundamentalmente qualitativa, porém, exige uma focalização da atividade pesquisante com o intuito de evitar qualquer interferência do subjetivismo, ou uma prisão ao objetivismo.

Interpretar a realidade vivida somente por meio de representações mecânico-geométricas é reducionismo. A metodologia cartesiana dominou a ciência por séculos, servindo como referencial exclusivo da verdade e excludente da diversidade de perspectivas e enfoques. Sua aplicação prática é a base para a tecnologia e o domínio exploratório e depredatório da natureza, com os desdobramentos da ameaça da insustentabilidade. A fenomenologia de Goethe não realiza uma sobreposição ao método cartesiano, oferece uma outra via de pesquisa, permitindo: uma nova relação com o objeto, uma formação diferenciada do sujeito, uma nova interação ser humano e mundo, um diálogo na natureza, com a natureza. Sua aplicação prática não cabe dentro dos termos utilitaristas, pragmáticos e exploratórios. Ela permite o estabelecimento de uma outra qualidade de relação, de um outro sentido de ser e atuar no mundo. 


\section{Referências}

AMRINE, F. The metamorphosis of the scientist. In: SEAMON, D.; ZAJONC, A. Goethe's way of science: a phenomenology of nature. New York: State University of New York Press, 2013. p. 33-54.

BORTOFT, H. Counterfeit and authentic wholes: finding a means for dwelling in nature. In: SEAMON, D.; ZAJONC, A. Goethe's way of science: a phenomenology of nature. New York: State University of New York Press, 2013. p. 277-298.

GOETHE, J. W. Analyse und synthese. In: . Naturwissenschaftliche schriften I. München: Deutscher Taschenbuch Verlag, 2000a. p. 49-52.

. Doutrina das cores. São Paulo: Nova Alexandria, 1993. . Erfahrung und wissenschaft. In: . Naturwissenschaftliche schriften I. München: Deutscher Taschenbuch Verlag, 2000b. p. 23-25. Máximas e reflexões. Rio de Janeiro: Forense Universitária, 2003. . Der versuch als vermittler von objekt und subjekt. In: GOETHE, J. W.

Naturwissenschaftliche schriften I. München: Deutscher Taschenbuch Verlag, 2000c. p. 10-20.

GUIMARÃES, L. A cor como informação: a construção biofísica, linguística e cultural da simbologia das cores. São Paulo: Annablume, 2004.

HEITLER, W. Goethean science. In: SEAMON, D.; ZAJONC, A. Goethe's way of science: a phenomenology of nature. New York: State University of New York Press, 2013. p. $55-70$.

HENSEL, H. Goethe, science and sensory experience. In: SEAMON, D.; ZAJONC, A. Goethe's way of science: a phenomenology of nature. New York: State University of New York Press, 2013. p. 71-111.

LINDHOLM, S. Inszenierte metamorphosen: Beuy's aktionen vor dem hintergrund von Goethes gestalttheorie. Freiburg: Rombach Verlag, 2008.

NEWTON, I. Óptica. São Paulo: EDUSP, 1996.

SEAMON, D. Goethe, nature and phenomenology: an introduction. In: SEAMON, D.; ZAJONC, A. Goethe's way of science: a phenomenology of nature. New York: State University of New York Press, 2013. p. 1-14.

SHOT'TER, J. Goethe and the refiguring of intellectual inquiry: from 'aboutness'-thinking to 'withness'-thinking in everyday life. Janus Head, New York, v. 8, n. 1, p. 132-158, 2005.

Artigo recebido em 06/02/2014. Aceito em 22/05/2015. 